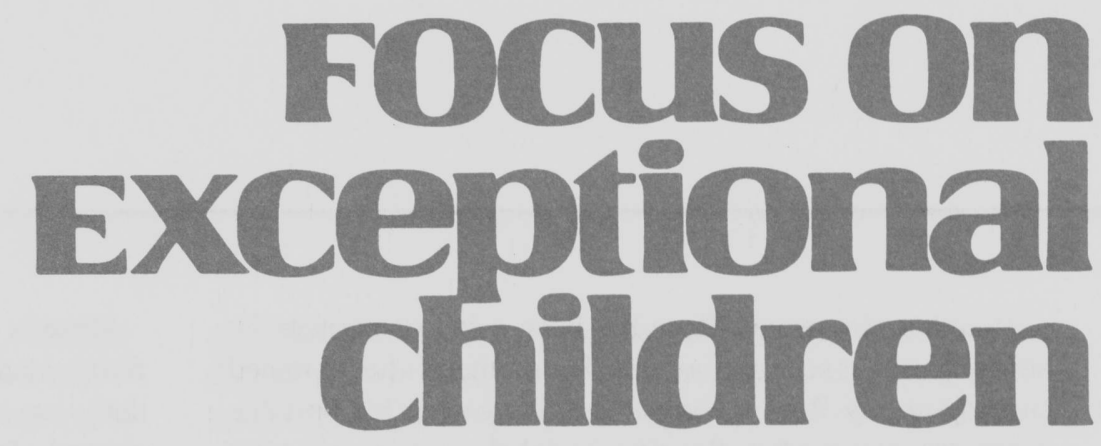

\title{
User Perspectives on Assistive Technology in Educational Settings
}

\author{
Bonnie Todis and Hill M. Walker
}

\section{ROSE AND HER ASSISTIVE TECHNOLOGY}

Rose $^{1}$ is an 11-year-old fifth-grade student in a small city in the Pacific Northwest. She is tiny and pretty, with long, shiny, dark hair, usually pulled back in a ponytail, sparkling blue eyes, and an engaging smile. She has cerebral palsy. She is unable to walk unassisted, but because she can support herself briefly with her arms, she is self-mobile in a variety of ways. Rose gets around her home by crawling and can pull herself up onto the couch. Handrails have been installed in the hallway to permit her to walk if she wishes. At school she uses a walker with wheels a couple of times a week to exercise her legs and arms.

The central component of Rose's mobility system is her motorized wheelchair. This is Rose's second power chair, recently purchased to replace one she had used for 6 years. The new chair features a customized seating system, electronic, programmable controls, and a joystick that swings out of the way to allow Rose to pull close to tables and desks of standard height. Rose also has a standard or manual wheelchair, which she uses when her power chair is being repaired or when accommodations are not available to transport her power chair.

Wheelchairs are a common sight at Rose's school, which houses the Orthopedically Impaired Program for the district. Although new wheelchairs generate a great deal of interest and are viewed almost as status symbols, in general nondisabled students and teachers regard them simply as tools students with physical disabilities use to propel themselves around the school.

Because Rose's upper body also is affected by cerebral palsy, she uses a number of adapted devices to expand her access to her environment and help her function independently. Adapted pencils, eating utensils, scissors, and other common tools permit Rose to function nearly independently when she eats and does school work, at home and at school.

\footnotetext{
${ }^{1}$ Names of all project participants have been changed, and information that could potentially identify them has been omitted or modified to protect their privacy, in accordance with confidentiality agreements established at the outset of the project.
}

Bonnie Todis and Hill Walker are affiliated with the Center on Human Development, University of Oregon, Eugene. 
Like her classmates, Rose has been using computers for several years at school. Last year her mother, Julie, obtained funding to buy Rose a computer of her own. This portable computer, mounted on Rose's wheelchair, is equipped with software for completing academic assignments. Her word processing program includes a word-prediction feature so Rose need type only the first letters of a word, then choose the desired word from a list. Because Rose uses only one finger on her right hand to type and tires quickly at the computer, the word prediction feature is an important time- and energy-saver.

The computer also has voice-output capability. Rose's speech is intelligible to people who are acquainted with her, but strangers have difficulty understanding her, and even her mother sometimes puzzles over a new word Rose speaks. Rose's computer allows her to display messages on the screen or, through voice synthesis, to produce them in spoken form.

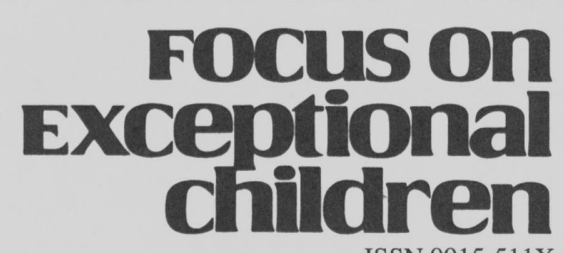

ISSN 0015-511X FOCUS ON EXCEPTIONAL CHILDREN (USPS 203-360) is published monthly except June, July, and August as a service to teachers, special educators, curriculum specialists, administrators, and those concerned with the special education of exceptional children. This publication is annotated and indexed by the ERIC Clearinghouse on Handicapped and Gifted Children for publication in the monthly Current Index to Journals in Education (CIJE) and the quarterly index, Exceptional Children Education Resources (ECER). It is also available in microfilm from Xerox University Microfilms, Ann Arbor, MI. Subscription rates: Individual, $\$ 30$ per year; institutions, $\$ 40$ per year. Copyright @ 1993 , Love Publishing Company. All rights reserved. Reproduction in whole or part without written permission is prohibited. Printed in the United States of America. Second class postage is paid at Denver, Colorado. POSTMASTER: Send address changes to:

Love Publishing Company

Executive and Editorial Office

1777 South Bellaire Street

Denver, Colorado 80222

Telephone (303) 757-2579

Edward L. Meyen

University of Kansas

Richard J. Whelan

University of Kansas Medical Center
Glenn A. Vergason Georgia State University

\author{
Holly T. Rumpler \\ Senior Editor
}

Rose is an independent and social young woman whose future plans include college and a career. She is a good student, has served in the student council, and this year was elected class secretary. She chats with her friends on the telephone, which is preprogrammed with their numbers so she can dial herself. She participates in horseback riding, swimming, summer camp, and slumber parties. She likes to help with household chores and uses a stander to position herself at the kitchen counter to help wash dishes and prepare meals. Her mother's attitude is that she does not want to suggest activities to Rose at which she will not succeed, but if Rose expresses an interest and accommodations can be worked out to enable Rose to participate, Julie goes to great lengths to make those accommodations.

Julie acknowledges that technology complicates as well as simplifies their lives. Last spring the van lift broke down, and the van was in the shop for days. When Rose got her new chair, she put a few gouges in the walls until the attachment for the portable computer was adjusted. Julie regards these as inconveniences that are part of living in a technological age. She believes the time spent obtaining, maintaining, and replacing Rose's technology is more than justified by the benefits it provides Rose.

\section{SARA AND HER ASSISTIVE TECHNOLOGY}

Sara is a 15-year-old student at a rural middle school. She has cerebral palsy - severe athetoid quadriplegia-and is

STATEMENT OF OWNERSHIP, MANAGEMENT, AND CIRCULATION

Date of Filing: October 15, 1993

Title of Publication: Focus on Exceptional Children

Frequency of Issue:Monthly (except June, July \& August)

Location of Known Office of Publication:1777 S. Bellaire Street, Denver, Colorado 80222 Location of Headquarters of Publisher: 1777 S. Bellaire Street, Denver, Colorado 80222

Name and Address of Publisher, Editor, and Managing Editor: Stanley F. Love, 1777 S. Bellaire Street, Denver, Colorado 80222 Owner: Stanley F. Love

Extent and Nature of Circulation: $\quad$ Average No. Copies Each Issue During

Single Issue Preceding 12 Months

Filing Date

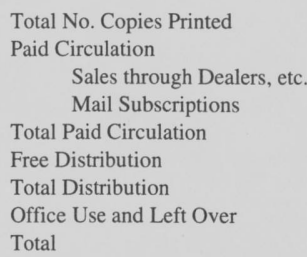


unable to support her weight or to grasp objects with her hands. She communicates primarily through eye gaze and a manual yes/no response; a slight movement with her right hand means yes, left is no. In several respects Sara is a typical adolescent. She has grown several inches in recent months. Her mother dresses Sara in "with it" fashions and applies a touch of eye make-up and blush before sending her off to school. Though normally cooperative and cheerful, Sara recently began displaying sullen behaviors that her parents and teachers interpret as adolescent rebellion. Sara is the only person in her school who has physical disabilities. She spends most of her day in a self-contained special education program, although testing places Sara in the lownormal range of cognitive functioning.

Sara has had her present motorized wheelchair (her first) 4 years. Before her growth spurt she was able to drive it independently, using a joystick in the form of a cradle for her right forearm. Now that the chair no longer fits, the seating system does not maintain Sara in a position from which she can maintain contact with the joystick. Exerting pressure on the joystick twists her body into a position that is aggravating her scoliosis and producing a number of other muscularskeletal concerns, not to mention being intensely uncomfortable and tiring.

Furthermore, in assessing the wheelchair, the occupational and physical therapists determined that the joystick had too much play. When this was corrected, they discovered that the chair would not track straight even when a nondisabled person drove it. Because Sara's parents cannot afford to replace the chair, the tracking problem was addressed by partially deflating one tire, and the problem of maintaining contact with the joystick was solved by raising the cradle and constructing a strap from pantyhose to hold Sara's arm in it. The problems with the wheelchair culminated with Sara's running into a door frame and breaking her leg.

Sara's communication system is augmented with a variety of technical and nontechnical devices. An E-tran board was introduced this year. This clear plexiglass board accommodates a variety of overlays: names of classmates, letters, numbers, and so on. By looking at an item on the overlay, Sara can indicate choices or respond to questions. A dedicated electronic alternative and augmentative communication (AAC) device with voice output was provided to Sara this year for the first time. This device is programmed with 32 phrases through which Sara can initiate interaction or respond to questions regarding common situations. The device has a second level programmed with letters of the alphabet so Sara can spell messages that are not prepro- grammed on her device. Because Sara cannot activate the device directly by pressing its keys, she uses a light scan system. Each phrase is illuminated in turn, and when the desired message is lighted, Sara presses her headswitch, which activates the device and produces the message in written and spoken form.

Sara does academic work on a computer, attached to her headswitch via an adaptive firmware card. Letters, punctuation marks, and symbols representing spacing and backspacing functions are displayed across the bottom of the screen. As the cursor scans across them, Sara waits until it reaches the desired symbol, than presses her headswitch, and the letter appears on the screen. Sara is an exceptionally good scanner and produces about five letters per minute.

All of Sara's assistive technology, except the standard wheelchair, stays at school. Her family says their house has no room for it and Sara has nowhere to drive her power chair in their rural area. Transporting it also is a problem, as Sara has grown too tall to fit in their minivan when she is seated in it, and the van is not equipped with a lift. Sara's mom says remembering to send the AAC device back and forth is too much of a hassle, and the messages programmed on it are not ones Sara needs at home. Her family believes they understand Sara's nonverbal communications well enough to meet all of her needs. Because the computer is not portable and others use it in the classroom, it, too, stays at school.

Those who know her generally agree that Sara has more to say than her current technology permits her to express, and that she is capable of using much more sophisticated equipment. The school staff particularly dislikes the AAC device, saying it is too slow and offers an inadequate selection of messages. Sometimes communications generated on the AAC device make no sense to the staff, and when they question her, she has no way to explain what she means. Neither Sara nor the staff seems to recognize that she could follow up by writing more detailed responses, on either the AAC device or the computer. Perhaps they do not suggest these alternatives because Sara's writing is hard to interpret. Because she did not have access to a means of expressive communication in her early years, her syntax is unconventional. Her writings often begin as coherent messages and degenerate into words strung together. When asked for clarification, she looks blank or changes letters at random until the screen is full of nonsense words.

Sara represented an enormous challenge to school staff during this, her first year at the middle school. She was at the same time the most physically disabled and the most cognitively competent student they had ever served in the 
special education program. The staff required most of the school year to feel comfortable tending to Sara's personal care-feeding, diaper changes, positioning, and stretching. Her technology represented another layer of responsibility, but one that was relegated to second place behind caregiving. Because the technology itself was not functioning well and seemed inadequate, the staff tended to forget to use it and to complain about it openly, often in Sara's presence.

The staff regards Sara as having a lot of potential for more independent functioning but also as having much to overcome: learned helplessness, delays in expressive language, and gaps in practical knowledge because of limited exposure to mainstream environments and systematic instruction. Her family regards her as bright and sweet. Increasing Sara's independence does not seem to be a goal for Sara's family. They plan to have her with them indefinitely. As for Sara, she seems to like new experiences and more independence, but sometimes when they entail new responsibilities she withdraws and refuses to participate. Sara's view of her future is unclear. Unaccustomed to being asked for her opinion on complex issues, she responds by looking confused or smiling.

\section{DEFINITION OF ASSISTIVE TECHNOLOGY}

The term assistive technology (AT) refers to mechanical, electrical, or computerized tools for enhancing the routine functioning of people who have physical disabilities (Scherer, 1993). AT includes

\begin{abstract}
any item, piece of equipment, or product system, whether acquired commercially off the shelf, modified, or customized, that is used to increase, maintain, or improve functional capabilities of individuals with disabilities. (34 CFR SS 00.16 Technology-Related Assistance for Individuals with Disabilities ACT, 1988)
\end{abstract}

In discussing AT, people tend to focus on high-tech devices such as power wheelchairs, AAC systems with voice output, sensory devices for people with visual or hearing impairments, computers, or sophisticated electronic environmental control devices. However, many people rely on low-tech AT for a variety of purposes. Some examples of simple assistive devices are nonmotorized or manual wheelchairs, communication boards or books accessed by eye gaze or pointing, and devices such as standers, seating systems, and reaching tools to help achieve independence in the activities of daily living. Other devices fit more properly into the category of adapted equipment-devices designed for the general population that have been adapted for use by people with disabilities. Examples of adapted equipment are spoons with built-up or curved handles, water taps using levers rather than knobs, and velcro clothing fasteners.

Until recently, AT in educational settings, and research on these applications, focused on students having disabilities in only one area-physical, visual, or auditory impairment (Behrman \& Lahm, 1984; Garner \& Campbell, 1987; Hagen, 1984). Rapid advances in technology in general and more participation of students with disabilities in regular educational settings have led to increased interest in AT applications for students with severe cognitive and multiple disabilities (Locke \& Mirenda, 1988; McGregor, Young, Gerak, Thomas, \& Vogelsberg, 1992; Romski \& Sevik, 1988). Today the average AT consumer uses eight devices (Barnicle, 1991), reflecting the variety of devices available as well as the interest in combining technologies to meet a range of disability-related concerns.

\section{BENEFITS OF ASSISTIVE TECHNOLOGY IN EDUCATION}

Research has demonstrated dramatic developmental, academic, and social benefits of some AT applications. Positioning devices allow students with physical disabilities to join classmates at tables, on the floor, or in a standing position (Hulme, Poor, Schulein, \& Pezzino, 1983; Trefler, Nickey, \& Hobson, 1983). Studies have documented the benefits of powered mobility for children as young as 2 (Butler, 1985; Verburg, Pilkington, Snell, \& Milner, 1985). Specific effects include higher frequency of self-initiated interaction with objects, spatial exploration, and communication with caregivers (Butler, 1985). Lott and Milner, (1984) reported major changes in cognitive and social skills in 10 children (ages 2 to 5) who learned to drive a motorized vehicle.

Personal computers provide both instruction and independence (Garner \& Campbell, 1987) for students with physical and cognitive disabilities. By using word processing, math, and drawing programs installed on personal computers, many students can overcome problems with fine-motor coordination that slow or prohibit writing and drawing (Bourland, Jablonski, Allen, \& White, 1984; Hofmeister \& Friedman, 1986). Besides giving access to instructional activities, computers also are used to train specific cognitive skills, including contingency awareness and means/end relationships (Behrman, 1984; Esposito \& Campbell, 1987). Current re- 
search on applications of personal computers in special education is directed at CD ROM access to dictionaries, encyclopedias, and other reference materials for students with learning disabilities (Anderson-Inman, 1992) and on text enhancement to improve reading skills of students with hearing impairments (Anderson-Inman \& Wood, 1992).

Alternative and augmentative communication holds the promise that students with speech and language disabilities might express their needs, make choices, direct their own care, and interact with peers in a spontaneous, natural way. Reported benefits of children's use of AAC include: (a) improved speech comprehension (Bricker, 1972); (b) increased speech production (Hobson \& Duncan, 1979; Kahn, 1981), or both (Kostantareas, Webster, \& Oxman, 1979); (c) improvements in attention span (Chamberlain, 1985); (d) better task orientation (Morrow, Burke, \& Buell, 1985; Osborne, Kosiewicz, Crumley, \& Lee, 1987); (e) improved social behavior (Cone, Anderson, Harris, Goff, \& Fox, 1978; Twardosz \& Jozwiak, 1981); and (f) fewer problem behaviors (Baumgart, Johnson, \& Helmstetter, 1990).

Recognizing the importance of technological support for school-age students, this type of support now is mandated through the 1988 revision of PL 94-142, the Individuals with Disabilities Education Act (IDEA). The act provides that, if a child with a disability requires AT devices or services to receive a free appropriate public education, the public agency shall ensure that the AT devices or services are made available to that child, as special education, related services, or as supplementary aids and services that enable a child with a disability to be educated in regular classes. Whether a child with a disability requires AT devices or services must be determined on an individual basis through individualized education program (IEP) and placement procedures (letter from Office of Special Education and Rehabilitative Services, J. Schrag to S. Goodman, August 10, 1990). Given this mandate and the rapid development of new technologies and AT products, we can expect AT to be introduced increasingly to students during their school years.

\section{CHALLENGES ASSOCIATED WITH ASSISTIVE TECHNOLOGY}

Rose's case study illustrates some of the potential benefits AT holds for students with severe and multiple disabilities. Unfortunately, our own research and that of others indicate that Sara's case study accurately depicts problems associated with the use of AT in educational settings that are all too well known by AT users, parents, school personnel, and other professionals.

Nearly one third of all purchased assistive technology devices are abandoned (Phillips, 1991), most often during the first year after they are recommended (Scherer, 1991). Obsolescence and simply wearing out the devices are not the major reasons AT falls into disuse. Reasons consumers give for not using AT are that: (a) they did not improve independent functioning, (b) servicing and repair were too difficult to obtain or too expensive, and (c) the device was too difficult to use, was unreliable, or required too much assistance from another person (Phillips, 1992; Blackstone, 1992). Other factors contributing to abandonment relate not to the technology itself but, instead, to circumstances surrounding its acquisition and use: changes in personal priorities for activities, changes in functional performance, difficulty obtaining devices from suppliers, and the AT user's lack of involvement in the selection process (Phillips, 1991, 1992).

\section{THE ASSISTIVE TECHNOLOGY PROJECT}

\section{Subjects and Data Collection}

The case studies and findings presented in this article were drawn from a 2-year qualitative study of the issues associated with AT in educational settings. Thirteen students, ranging in age from 4 to 20 , participated as primary respondents. These students have a variety of disabling conditions and use an array of assistive technology.

Each respondent was assigned a field researcher, who conducted a weekly participant observation over a 12month period, usually at school but occasionally also at home or in other community settings. During the 2- to 4hour participant observations, the field researcher took no notes but simply observed events and interactions in the setting. Further, field researchers conducted interviews with parents, teachers, and other staff members. The interviews were open-ended and unstructured, so the interviewees could raise topics associated with the respondents or with their technology that they considered important. The field researchers asked questions and checked perceptions about procedures and interactions they observed. They also learned the history of the devices, including how they were acquired and how training was conducted. The interviews also provided an opportunity for teachers and specialists to relate their broader experience, over the course of their careers, with other students who used AT. 


\section{Data Analysis}

Data for this project were in the form of interview transcripts and field notes. All data were entered into a computer and coded by topic area, using a data-sorting program. Themes were identified across subjects, and as additional information was collected, it was examined for new themes and evidence either supporting or disconfirming themes identified previously. Themes were tested further by asking the subjects to comment on their validity. In the second year new subjects were added to investigate aspects of some themes that were inaccessible in the original group of subjects.

Case studies of all respondents were prepared and presented to a group of professionals including a pediatrician, a child psychologist, a physical therapist (PT), two mobility training specialists, a speech pathologist, an AAC specialist, and an occupational therapist (OT), all highly experienced in assessing and training children with disabilities to use AT. They provided perspective on how the respondents' experiences compared with those of other children they observed using assistive devices and suggested questions to explore through further observations and interviews.

In this article we discuss the themes and issues surrounding AT use in education as identified in the Assistive Technology Project. Because the study involved students at different stages of acquisition and use of AT, tracked students over a 2-year period, and examined each student's history with AT, it provides insight on how AT use is affected by educational transitions, development, and other factors over a student's school career. The data collected represent the perspectives of all AT "users," including parents, professionals, and classmates, as well as the student users themselves. As the article illustrates, the complex issues surrounding AT cannot be understood without accessing and understanding each of these perspectives. The article is organized by topics around which technology issues tend to cluster: evaluation, funding and acquisition, training, and daily use.

\section{EVALUATION}

\section{Rose}

Rose and her mother worked closely with the PT who conducted the evaluation for selecting her new wheelchair. They considered her current mobility needs and how her mobility will be impacted by physical and social changes over the next 5 years (the chair's projected lifetime). Priori- ties for Rose were speed, size, appearance, being able to reach all controls herself, and being able to pull her chair close to tables and desks of standard height.

The evaluation that led to selecting Rose's portable computer likewise was a team effort involving Rose, her mom, a PT, an OT, and an AAC specialist. The evaluation began by looking at how Rose currently uses a standard computer and how she might use a computer over the next several years. The team then considered what features not present in standard computers would be beneficial in the future. Portability, word prediction, and optional voice output emerged as priorities. No further evaluation was needed to determine the best means of access, as Rose can use direct selection with a standard keyboard.

\section{Sara}

Sara's physical disabilities prevent her from directly accessing a computer and require her to use an unconventional method to drive her wheelchair. Her cognitive level is difficult to assess because of deficits in expressive language and gaps in practical and academic knowledge.

The challenges and potential Sara presents, in terms of accessing and benefiting from assistive technology, generated interest and concern among technology experts throughout the state. Professionals from local, regional, and state special education offices and medical facilities spent hours with Sara, trying various devices and switches by which she could access and control them, and fashioning unique equipment for her when the perfect ready-made solution could not be found. These professionals gave willingly of their time to conduct evaluations because, unlike many students with severe physical disabilities who also have severe cognitive disabilities, Sara clearly understands the purposes of the assistive devices she uses and she needs little training to benefit from them.

Sara was evaluated at a regional medical center to determine what kind of AAC device should be purchased for her. Although the school system could be required to provide a device for the remainder of her school years, the team agreed that Sara should have her own device, one she can continue to use in adulthood and that has more features than the school district might deem necessary strictly for school use. The AAC device recommended combines features of the present AAC device and the computer: Many phrases can be preprogrammed and activated by "typing" a single letter, and Sara also will be able to type messages as she does on the computer. Word prediction will increase the 
speed with which Sara can communicate. The messages can be displayed on a screen, on a paper tape, or through voice output.

\section{Importance of Evaluation}

From Rose's and Sara's case studies one might be tempted to conclude that a major factor accounting for their differing degrees of success and satisfaction with AT is the extent of disability of each. Undeniably, Rose's level of cognitive functioning and ability to access her computer directly and use a simple joystick to drive her wheelchair facilitate her use of technology. AT specialists, however, are quick to point out that students with disabilities similar to or even more severe than Sara's can be successful AT users. Advances in methods of access and professionals' experience in working with AT users who have severe disabilities have contributed to students like Sara being viewed as simply more challenging in terms of evaluation and AT recommendations.

Regardless of the user's type and extent of disability, evaluation is crucial to successful AT outcomes. Goodnessof-fit between device and user affects access, rate, and comfort, and ultimately utility and satisfaction. Assuring goodness-of-fit requires assessing the user's unique constellation of abilities and disabilities, familiarity with technology options, knowledge of the user's goals for AT use, and consideration of the interaction between the device and setting variables, including other devices the user employs. Unfortunately, the ideal evaluation, in which the full range of devices is considered against each of these factors, is difficult to accomplish.

\section{The Evaluation Process}

\section{Referral}

Referrals for AT evaluations often are generated by a doctor, parent, or teacher who has heard about other children with disabilities who have benefited from AT devices. As the general public becomes more familiar with computer technology and more aware of how rapidly technological advances are occurring, referrals are driven more and more by the sense that something "out there" would help certain children function more independently and more "normally" in spite of their disabilities. Parents are becoming aware that, under IDEA, schools are required to provide whatever technology and related services a student needs to receive an appropriate education. The early intervention emphasis in special education and research on the developmental benefits of some types of AT use have resulted in referrals to conduct mobility, AAC, computer, and other types of AT evaluations for children age 2 or younger.

\section{Evaluation Team and Setting}

AT evaluations usually are done by a specialist or a team including OT, PT, AAC specialist, speech and language specialist, and pediatrician. Evaluations often are conducted in a medical setting, as funding may require a doctor's prescription or proof of medical necessity. Evaluation teams whose backgrounds are primarily in the medical field may not have school applications of AT clearly in mind and may not have opportunities to observe AT use in education settings. Particularly with preschoolers, the developmental benefits of a mobility or AAC device may be more salient to the evaluation team than possible academic applications.

Even when school districts are responsible for the evaluations, they may be conducted in clinical rather than classroom settings, and the input of teachers, particularly regular classroom teachers into whose classrooms the student may be mainstreamed, may not be sought. Faced with shrinking budgets and a mandate to provide AT for school use, schoolbased evaluations may be influenced by the cost of the device and by availability of district-owned AT that can be "recycled" from graduating students (Blackstone, 1992). Whether conducted by medical or school staff, home and community use of the device may be considered only in passing, and parents and other student advocates may not have the background in AT to suggest or insist upon a more comprehensive evaluation.

\section{Evaluation Procedures}

Ideally, the evaluation team would conduct extensive interviews and observations in home, school, and community settings, to determine student preference, family values, and short- and long-term social, academic, and personal goals. Then, based on research with students similar to the target student on the efficacy of all types of AT, the team would select several devices to try with the student, perhaps first in the clinical setting but also in natural surroundings. The team would make a preliminary recommendation, but before purchase the student would use a loaner device, identical to the one being recommended, for at least several weeks. Problems of access and other glitches would be treated as serious issues. If these could not be resolved to the user's satisfaction, another device would be selected for a trial period. 
In practice, the evaluation process is complicated by a number of factors. As discussed above, evaluations usually are limited to clinical or classroom settings. Technological advances are occurring so rapidly that evaluators have difficulty simply keeping up with literature on the types of devices available, much less finding objective data on the efficacy of new devices. Often, evaluations are limited to devices clinicians already are familiar with through past experience or through sales literature developers and vendors send to them (Grady, Kovach, Lange, \& Shannon, 1991; Hyman, Miller, \& O'Brien, 1988; Mortola, Kohn, \& LeBlanc, 1989). As a result, the range of devices considered for a given child is severely restricted. In some cases, evaluation teams may be tempted to recommend "cutting edge" devices that appear to have features beneficial to the student, but are of unproven effectiveness.

Another common evaluation issue is the failure to adequately address access. Access sometimes is treated as a separate issue: First get the device, then figure out how the student will access it. Experienced evaluators have learned that subtle differences in the way access is achieved can have great impact on how, or whether, a person uses the device. Two students using identical computers, one with direct access and one with a headswitch, may have a vastly different amount of satisfaction with the device in terms of effort expended, speed, and the way others perceive it. Especially when dealing with young children, evaluators may hope or assume the student will develop the strength or dexterity to access the device after purchase, and loaner devices seldom are available to test this assumption. Unfortunately, in many cases the physical demands of AT turn out to be greater than the benefits the user realizes from it, and lack of adequate access is a leading cause of device abandonment (Scherer, 1993).

Evaluators usually prescribe a device to meet the student's present needs, with the intention of upgrading as the student's needs and skills change and technology advances, but cost and funding often make this unrealistic. Because AT is expensive, parents, school districts, and funding agencies want to purchase devices students can use over a number of years. The evaluator's task is to try to find a device that satisfies this requirement but is not so sophisticated that the young student has to devote years learning to use it.

Another factor that can complicate evaluation is pressure to recommend and provide AT, without regard to student goals and circumstances. An evaluation may determine that the student indeed can access the device in question, but the values, goals, and circumstances of the student, family, and school may be not be consistent with using the device. Should a voice-output AAC device be recommended if the student prefers another communication method? Should a high school student with severe retardation have a computer for word processing even if he or she can neither read nor spell? The risk of providing AT in situations like these is not only that the devices will sit unused but, more important, that tensions will develop between home and school over whether and how the device is to be used in each setting, and that "how to get the student to use the technology" will become the focus of the student's school program.

The factors affecting evaluation may be particularly complex when the student being evaluated is a preschooler. Given the growing evidence of developmental benefits of early exposure to self-mobility, AAC devices, and computers, the "downward extension" of AT is becoming more common. A PT who participated in the Assistive Technology Project commented, "Ten years ago it was unusual to encounter a 3-year-old who had had an evaluation for power mobility. Today it is unusual to encounter a 3-year-old who hasn't [had such an evaluation]." The evaluators' reasoning is that, if the device has developmental benefits, the earlier it can be provided, the less the target area will be delayed in development.

Following this reasoning, many young children by definition lack the physical and cognitive skills to use their devices effectively when they acquire them. In actuality, use of the device may require skills and cognitive development not present in nondisabled children of the same age, and in some cases the student may not ever develop the cognitive skills to operate the device. Because AT is expensive and many parents come to regard the device as the key to their child's academic and social success, years may be spent in training the child to use the device at the expense of other academic and social goals.

An area too often overlooked during evaluation is how the technology will impact the setting in which it is used: how it will interface with other technology the student uses, where it will be placed in the student's various environments, and what other accommodations may be necessary to help the student make full use of the technology. Although factors such as these should not cast the deciding vote on whether to recommend a given device, evaluators should recognize that a device cannot effectively produce positive outcomes if environmental and social circumstances prevent the individual from using the device in the settings in which it is needed. 


\section{FUNDING AND ACQUISITION}

\section{Rose}

Although her parents are divorced, Rose is covered by her father's medical insurance, which has paid for some of her mobility equipment. Based on her mother's income, she also qualifies for Medicaid, commonly known as a "medical card." The computer was funded in large part by the medical card, which pays for AAC devices when applicants demonstrate "medical necessity." In this case, the argument was that, if Rose had a medical problem, she might be unable to describe her symptoms verbally so medical personnel could treat her appropriately.

Over the years Rose's mother has become knowledgeable about other sources of funding for assistive technology. When the van lift broke, for example, she contacted a private fund that provides small grants to families to acquire and maintain equipment.

\section{Sara}

Sara has medical insurance through her father's employment, but the family income is above the limit to qualify for a medical card. The insurance policy has paid for part of the cost of Sara's wheelchairs, but making up the difference, as well as purchasing other adaptive equipment for Sara and making modifications to their home, has placed a financial strain on the family. As her mother stated:

\footnotetext{
We've spent too much money. Everything we do is getting things for Sara. Sara always needs something, and it gets real frustrating - not so much that [our other] daughter gets left out-it's like, we can't afford to camp! We haven't gone camping in two years and that's real frustrating for my husband and me.
}

Knowing the family's financial situation influenced the recommendations of professionals who conducted Sara's AT evaluations. Even though Sara's wheelchair clearly is worn out and outgrown, the recommendation was to purchase a new seating system that might provide enough support to permit her to drive the chair for a few more years. The seating system can be moved to a new chair when she eventually gets one. The team members-even the PT who would like to see Sara have a new wheelchair-agreed that purchasing an AAC device should be a higher priority because being deprived of an appropriate device has so obviously hampered Sara's linguistic, academic, and social development.
Although the new device promises to improve Sara's ability to communicate, the school AAC specialist, and indeed the specialists who recommended the device, are aware of more sophisticated devices that might be even more appropriate for Sara. These devices, however, are considerably more expensive than the one recommended, which represents a compromise between what Sara needs and what her family might be able to afford. The evaluation actually was conducted, and the recommendation initially made, 3 years ago, but Sara's family had no idea how to come up with $\$ 8,000$ to purchase the device. This year Sara's mother followed up on suggestions from the AAC specialist and was able to piece together several thousand dollars in donations. At the end of the year, however, Sara's mother reported that no more funds appeared to be forthcoming, and the family still is far short of its goal.

\section{The Cost of Assistive Technology}

Several factors contribute to the high cost of assistive technology. As more students and adults with disabilities are living and working in mainstream settings, the demands they make on AT present new challenges to developers. In response, developers invest money in research and development to improve existing products and to design new ones. Production is on a relatively small scale, as AT constitutes a "niche" rather than a mass market (Moore, 1991), and production costs therefore are relatively high. Devices often must be customized further after they are purchased, to meet specific positioning or access needs of individual users.

Auxiliary equipment and adaptations sometimes add greatly to the cost of a device. A power chair may require a van with a lift and home adaptations. An AAC device or portable computer may necessitate wheelchair modifications such as mounting brackets or switches. To new AT users and their families these items may seem like "hidden costs," appearing weeks or months after purchasing the device itself but without which the device cannot be used to achieve user goals.

Assistive technology also entails maintenance and replacement costs. Maintenance might include not only the cost of parts and labor, which may be highly specialized and expensive, but often time and money to take or send the device some distance to the nearest repair center, and perhaps rental of a temporary replacement device. Families such as Sara's struggle with the decision of how long to contend with increasing repair costs before confronting the even greater cost of replacing an outgrown or worn-out device. Students like 
Sara may find themselves in a kind of limbo, with goals and activities on hold until the new chair or the new device can be purchased. The old device may fall into disuse, or continued use may present health or safety concerns.

\section{Funding Sources}

Private medical insurance and state and federal medical insurance are two major sources of funds of AT for students. Other sources include funds established through court awards, foundations and trusts, local service agencies, grants, and private donations. Families and professionals may combine funds from several of these sources to pay for an expensive device.

Private medical insurance companies vary greatly in terms of what types of devices they will pay for and how much of the cost they will bear. As a rule, wheelchairs are funded more readily than other types of equipment, because of documentation showing that proper positioning prevents postural problems that could necessitate future surgical intervention. Some private insurance companies will, like Medicaid, fund an AAC device if it qualifies as a medical necessity - that is, the user needs it to obtain help in an emergency or to describe physical symptoms to medical personnel.

As noted, school districts now are required to provide AT and related services if the student needs them to obtain an appropriate education. Districts vary in their interpretation of this mandate and in their ability and willingness to comply. The law does not require the schools to purchase the AT devices but only to make them available to students. Districts may ask, but not require, families to use their insurance or other sources or funds to purchase devices. ATs purchased by schools are the school's property, for students' use only until graduation. Many families try to access funds to purchase ATs for their children to ensure that they will be able to continue to use them once they have left school.

\section{TRAINING}

\section{Rose}

When she got her new computer, Rose went to the resource room every day for about 45 minutes to learn how to use it. She worked with teaching assistants who were familiar with a variety of computers they had encountered around the school but not with Rose's new computer. In the training sessions Rose and whatever assistant she happened to be working with engaged in trial and error as they learned together the features of her computer. At the end of each session, Rose knew at least as much about the system as the assistants did, and she practiced what she had learned throughout the day.

Rose needed no training to use her new power chair. The week she got it, she took it to Camp Fire camp and drove it independently over different types of terrain.

\section{Sara}

Staff members at Sara's school received training at the beginning of the school year from several regional specialists. A PT familiarized them with Sara's wheelchair, demonstrated how to use the stander, and showed them her stretching exercises. The OT showed some of the assistants how to feed Sara. The speech and language specialist offered suggestions for improving Sara's syntax, and the AAC specialist showed them how to program her AAC device, position the headswitch, and use the adaptive firmware card to give Sara headswitch access to the computer.

Because Sara did not have a full-time aide, interacting instead with all members of the special education staff, the specialists tried to train as many of the staff members as possible in as many areas as possible. Staff members who didn't use Sara's technology every day, however, forgot much of what was presented in the inservice training. Although specialists returned once a week to provide support and answer questions, the classroom staff seemed to think help was never there when equipment acted up or when Sara wanted to use it in a new way.

When specialists did visit the classroom, training was aimed at the teaching assistants, not at Sara. Not wanting to interfere with classroom management or instruction, specialists were reluctant to intervene directly with Sara-to remind her how to save or print a document she had created on the computer, for example.

Training in the powerchair was curtailed because of problems with the joystick and seating system.

\section{Training Issues}

Once the student acquires a device, responsibility for training typically falls to the school system. AT usually is recommended for children primarily to provide access to educational opportunities, and the school system is viewed as the logical source of training to accomplish this goal. In many cases, the school district will have conducted the eval- 
uation, recommended a specific device, and perhaps provided the device for the student's use. In fact, if another agency conducted the evaluation, school personnel may question the appropriateness of the device.

Teachers and school-based AT specialists may feel "stuck with" whatever the parent has chosen, having no input into selecting the device, but responsible for teaching the student to use it. Parents who have gone to the trouble and expense of obtaining AT devices for their children before they started school, or without waiting for a school recommendation, naturally are emotionally and financially invested in seeing the child receive adequate training to fulfill the promise it holds for independently performing school activities. Thus, the training process can be complicated by differences of opinion over evaluations and recommendations that occurred years earlier.

Because teacher preparation programs, even in special education, usually do not include specific instruction in technology applications, the classroom staff may not be aware of the purpose and potential benefits of AT, much less be prepared to train the student to use it. Although computers have been in schools for more than 10 years, they only recently have found their way into special education classrooms, so the staff may not be familiar with even mainstream computer technology, let alone the complex adaptations made to permit access for students with disabilities. In our experience, much of the concern teachers express about the barriers mobility and communication technology may present to peer interaction reflects their own discomfort with unfamiliar, intimidating devices.

Training of classroom staff often falls to one or more district or regional specialists, who tend to be more experienced and comfortable with technology in general than many other school personnel. Specialists are likely to be familiar, either through research literature or personal experience, with students who have benefited from AT, and usually are highly motivated to help students with disabilities benefit from using devices.

Often the specialist trains one (or more) member of the classroom staff, who in turn trains or assists the student in using the technology. As Sara's case illustrates, this training model presents several challenges. "Getting everybody in the same room at the same time," so the entire staff receives training is difficult, especially if the student interacts with many support personnel throughout the day. Also, the position of special education assistant is characterized by low pay, high stress, and high turnover, so new staff members may have to be trained frequently. Specialists qualified to conduct training usually have large caseloads of students to serve, so the time they have available to conduct formal training and provide support is severely restricted.

Classroom staff personnel participating in our study indicated that their formal AT training did not necessarily cover what they needed to know to help students with their devices. They pointed out that, "There are always glitches ... and they happen only when the specialist isn't there." When staff members referred to the need for more "training," they often meant more support from specialists for day-to-day use of ATs.

Perhaps the most critical shortcoming of most AT staff training is that it covers the technical aspects but neglects discussion of the purpose of this technology. The specialist conducting the training may assume that the teacher has familiarized the rest of the staff with the goals and values underlying an individual student's use of a device. Specialists may steer clear of this area because of time constraints and because they do not wish to appear to be encroaching in the teacher's area of expertise-setting and meeting instructional goals. Failing to link operation of the device to student goals, however, contributes to the problem of classroom activity focusing on the technology rather than on the goal the technology was acquired to achieve. Staff training must emphasize that the goal is not just to teach the student to use the device but, rather, to show the student how to use the device to complete specified tasks and work toward IEP goals.

One purpose of training classroom staff is to minimize the time students spend in one-to-one training with a specialist. Ideally, students should begin using AT devices as soon as possible in the context of academic work and social interaction, building skill in using the device through practical application, with support as needed. If training in use of the device is needed, training timelines must be developed and followed. Without these guidelines, and frequent review of the student's academic, social, and personal goals related to use of the technology, training to use the device or to increase speed and accuracy can stretch on indefinitely at the expense of other instruction.

\section{DAILY USE OF ASSISTIVE TECHNOLOGY}

\section{Rose}

For the most part, Rose's assistive technology functions for her in the way intended. In a few situations, however, Rose's assistive technology was not used, either because of oversight or because making arrangements to accommodate it 
seemed too difficult for the staff to arrange. The school bus used to transport Rose's classmates for field trips is not equipped with a wheelchair lift. On these occasions Rose travels in a van driven by a teaching assistant. If the van has a lift, she is able to use her power chair, but if it doesn't, or if a car must be used instead of a van, Rose ends up in her manual chair, dependent on aides for a function over which she usually has complete control. Curiously, arrangements are not made to have peers travel with Rose in the van or car, so on these special occasions she also is socially isolated for much of the time and misses out on the school bus interaction.

A more serious situation arose during the fall of Rose's fifth-grade year. By the end of fourth grade, she was using her computer independently in the regular classroom. The next year, Rose was assigned two teachers new to the school-her fifth-grade teacher and the special education teacher. The special education teacher was aware that Rose had her own computer but assumed, since she never had it mounted on her chair, that she used it at home to do homework. Rose's mother assumed that the computer was being used at school as it had been the previous year. Rose didn't mention the computer. She apparently was overwhelmed with adjusting to her new teachers, especially her fifthgrade teacher, who was just out of college and was struggling with classroom management.

In November, when Rose's mom learned that the computer wasn't being used at school, she contacted the special education teacher, who immediately located it in a closet. Rose brushed up her skills in the special education classroom but did not have many opportunities to use the computer in class. Uncertain about how Rose should use the computer to complete assignments, her teacher was unwilling to ask the special education staff for help.

\section{Sara}

Staff members often forget to give the AC device to Sara. Sometimes when she has access to it and produces a message, such as "I'm hungry" or "I need to have my diaper changed," they discuss among themselves or ask her directly whether she "means it" or is just playing. Sometimes they acknowledge the legitimacy of her request, but may delay a long time before responding. Sara doesn't repeat her requests, perhaps because she is too polite, or perhaps because staff members may take away the device if they think Sara is teasing them. Sara seldom uses the AAC device to interact with peers. Most of the programmed messages relate to personal care needs, and her classmates and peer tu- tors are too impatient to wait through the slow light-scanning process for messages Sara generates herself.

Sara attends a language arts class for students with learning disabilities, accompanied by a peer tutor or teaching assistant who sets up the computer and adapts the class assignments to Sara's skill level. One day the class was given a multiple-choice test pertaining to a novel the teacher had read to them. The other students circled the letter of the correct response. Sara was instructed to copy the question and all the answers to each question, then go back and put an $x$ by the correct answers. Sara likes to work on the computer and does not seem to mind copying rather than composing.

Early in the year the speech and language specialist spoke with the special education staff about the importance of not putting words in Sara's mouth when she works on the computer and encouraged them to deal with her syntax errors after she had completed an assignment. None of the teaching staff, except the head teacher, who seldom worked directly with Sara, knew that her software had backspace and insert functions, so correcting meant erasing back to the point of her first error and having her reenter everything after that. Because inputting letters with the headswitch and scanner is time-consuming and physically tiring for Sara, she seldom made corrections.

The AAC specialist has tried to impress upon Sara's mother and the classroom staff the importance of encouraging Sara to develop skill with the AAC device and to work on her spelling and syntax on the computer, because her new AAC device will combine features of both devices. School staff and family members seem to think that Sara is wasting her time with her current AAC equipment and talk about how much improved her quality of life will be when she gets her new AAC device.

\section{INTERACTION OF FACTORS AFFECTING IMPLEMENTATION}

Rose's and Sara's stories help us understand how issues relating to evaluation, cost, selection, and training interact to impact the student's daily experience with AT. We cannot safely assume that a student entering a classroom with an assistive device has been evaluated adequately, that the best device has been selected, that adequate training has been provided, and that ongoing support is available to student and staff. Rather, we have seen that, when not included in the evaluation process and not trained and supported adequately, even well-intentioned school personnel fall into 
patterns of underutilizing AT or focusing on technology use rather than on the goals it was designed to help reach. Other factors contributing to problems in implementing assistive technology include differing views on AT goals and conflicting demands on school personnel.

\section{Parent and School Perspectives on Student Assistive Technology Goals}

Family values and parental views of the student impact acquisition and implementation of assistive technology, as Rose and Sara demonstrate. Rose's family's view of her and her view of herself are fundamentally different from Sara's self-image and her role in her family. These differences carry over into school and community settings and impact their use of AT. Selecting and maintaining appropriate AT are priorities for Rose's family because the goals with which this technology is associated-more independence, social interaction and academic learning-are high priorities for them. Even though funding is not as available for technology for Sara, and her technology needs are complicated by her more severe disabilities, Rose's access to appropriate technology, her independence, and much of her academic competence can be traced to her mother's persistent efforts to provide opportunities consistent with her view of Rose as a capable, normally developing child.

In contrast, Sara's family views her as dependent on the family for all her needs, now and for the future. Her technology has been acquired mainly to facilitate caregiving or, more recently, in response to the agenda of professionals whose view of Sara as a young woman with the potential for independence in mobility and communication are not necessarily compatible with those of her parents. This difference in views has not resulted in open conflict, but it has contributed to frustration, to a lack of continuity in Sara's using AT, and to confusion over the goals of Sara's school program.

With other students in our study, differences in parental and professional views of the student's potential for independent use of AT and disagreement over long-range goals have led to conflict. Should the student continue to work on spelling, according to the parents' wishes, even though the student has made no progress for several years, in the hope that she eventually can use the computer as a communication device? Or should the student pursue other options for AAC and use the computer to play games with classmates, developing social and leisure skills? Should a student continue to work on independent mobility in community settings even though his family has no intention of ever letting him leave the house by himself? These and similar questions are not answered easily. They require honest exchange of views among parents, teachers, and students over the course of the student's school years, examination of family and school values, and frequent evaluation of classroom practices to ensure that goals and values are driving daily school activities.

\section{DEMANDS ON SCHOOL PERSONNEL}

As devices age and school resources shrink, management of technology becomes more difficult. Under these conditions, the focus can shift from applying AT to meet academic and social goals to managing the technology itself. Rose's field trip illustrates how even well-intentioned, well-trained school personnel can lose sight of student AT goals temporarily when confronted with complex and unique demands on their time, energy, and financial resources. Unfortunately, Rose's experience is not unusual. Many other examples are found in our data of school staff overlooking issues of selfpresentation, social interaction, self-image, and independence related to use of technology in favor of convenience, costcutting, and staying on schedule.

Sometimes a staff member is faced with a dilemma: Which is more important for the student- to be on time for his mainstream science class or to drive himself to class, even if he comes in late? Resolution requires discussion with the student, teachers, and parents of the relative importance of values such as independence, self-presentation, and responsibility for managing time. Maybe a discussion of the school's policy on tardiness with regard to wheelchair users is in order. Too often, however, no such discussion, or even any consideration of the issues involved, is forthcoming. More likely, the teaching assistant who drives a student's chair for him may not even be aware how the student and his peers perceive her actions.

Other examples of how pressures on school staff can lead to applications of AT that are not consistent with student goals, or even work against them, are:

The computer intended to let a student participate with her peers on class assignments is set up in the corner, where she works with an adult while the other students work together in groups.

$\square$ Preschoolers are instructed not to touch their classmate's AAC device and not to "bother" him while the specialist is there to teach him how to use it to interact with them eventually. 
Teachers request that a young student leave his motorized wheelchair at home because they are concerned about the safety of other students, and much of the class interaction takes place as students sit in a circle on the floor. Observation reveals that, although this is true, a great deal of interaction also occurs as students make transitions from one activity to another, during which time the student with disabilities sits on the floor waiting for an adult to move him.

\section{RECOMMENDATIONS}

The above examples illustrate the need to be thoughtful and planful when using AT in educational settings and to provide adequate support that will allow the staff to evaluate how daily activities contribute to meeting the user's goals and are perceived by other students. AT users, families, and professionals must work together to:

\section{Identify student goals and values.}

School personnel must have a clear idea of the relative importance of the student's academic, social, and personal goals and of the future expectations of the student and his or her family. Understanding these values will help resolve daily dilemmas arising around the use of AT and will help staff prioritize activities when conflicts arise.

\section{Tie the use of technology to academic, social, and per- sonal goals.}

Student goals and the part AT plays in reaching those goals must be the driving force behind AT acquisition, training, and use. These goals must be specific, and progress toward them must be measurable. To write in an IEP, "Mary will use her computer in the second-grade math class" is not sufficient. A goal this vague leaves the way open for Mary to spend a year working on speed and accuracy or playing games that have no relation to what the rest of the class is doing in math. A more appropriate goal is: "Mary will learn addition and subtraction facts from 0-20 with 98\% accuracy. She will use her computer to practice and take timed tests."

\section{Reevaluate frequently.}

Having specific, written goals permits the staff to evaluate progress toward those goals objectively. Progress should be assessed frequently, at least monthly. Lack of progress signals the need for a change-in materials, instruction, or placement.

Frequent evaluation is important particularly when a student is being trained to use a new AT device. Parents and staff should agree upon the time allotted for training. Objective measures of operation of the device should be tracked, and if progress is not steady, modifications should be made. If, after modifications and careful training, the student is not operating the device independently at the end of the agreed training period, appropriateness of the device should be reconsidered. As soon as possible, the student should leave the training setting and begin to use the device for classroom activities. Training can continue and skills can be developed as the student uses the device to do academic and interactive tasks.

Evaluation should take other forms as well. Staff members should step back from their activities from time to time to look objectively at the activities they ask students to do and the way in which they ask students to interact. Falling into habits that foster dependence or prevent students from progressing toward goals is an easy trap. Some questions to prompt staff awareness of these patterns include:

What is the purpose of this activity? (Should the student continue to work one-on-one with the specialist to improve speed and accuracy on his AAC device when the stated goal is to increase his interaction with other students?)

$\square$ What is the role of technology in this activity? (Why is the student working alone on math facts on his computer when the rest of the class is working in groups on a fraction activity? Is the role of the computer to integrate him into the class or is it to keep him busy while the teacher instructs the other students?)

$\square$ How is the student perceived by other students in performing this activity? (Does she still need a full-time adult assistant? How does this affect other students' perceptions? How would their perceptions change if she were to boot her own disk, drive her own chair, ask classmates for help when needed?)

$\square$ Could the activity be accomplished in a way, with or without technology, that works toward the student's academic goals, builds the student's independence, and increases interaction with peers?

School staff and specialists must take time to consider these questions, not only from their own perspectives but also from the perspectives of the student user and his or her classmates. 


\section{SUMMARY AND CONCLUSION}

Like the blind men examining the elephant, observers of AT use in education settings attribute problems they encounter to a number of sources: It's an evaluation issue; it's a question of keeping current with technological advances; it's a lack of staff training; it's funding; it's maintenance; it's design; it's poor student training; it's lack of parental support; it's careless implementation. This article has attempted to illustrate that it is all of these, at different times, and to a different extent with each student, and that all, like the parts of an elephant, are interrelated.

Assistive technology has an important role to play in the education of students with disabilities, and that role will increase as technological advances are made and individuals with disabilities are increasingly included in their communities. Successful application of AT requires that professionals responsible for recommending AT devices to students and their families acknowledge the complexity and interaction of the issues relating to it.

Educators seeking to optimize the impact of AT for students with disabilities also must consider the several perspectives and sets of values that impact AT use: those of the user, parent, specialists, special education teacher, regular classroom teacher, teaching assistants, and classmates. Each of these individuals has an important role in assuring that technology fulfills its promise to assist, rather than complicate, the process of educating students with disabilities.

\section{REFERENCES}

Anderson-Inman, L. (1992). Project SUCCESS: Students using cognitively-based computer enhanced study strategies (Proposal submitted to Office of Technology, Educational Media, and Materials for Individuals with Disabilities, Office of Special Education Research, Washington, DC). Eugene: University of Oregon.

Anderson-Inman, L., \& Wood, W. (1992). Project LITERACY-HI: Literacy improvement via text enhancements and reading assistance for children and youth with hearing impairments (Research proposal submitted to Office of Technology, Educational Media, and Materials for Individuals with Disabilities, Office of Special Education Research, Washington, DC). Eugene, OR: Cascade Program for the Hearing Impaired.

Barnicle, K. (1991). Evaluating assistive devices: What you need to know. Proceedings of the 6th annual conference: Technology and persons with disabilities (pp. 43-52). Washington, DC: Rehabilitation Engineering Center, National Rehabilitation Hospital.

Baumgart, D., Johnson, J., \& Helmstetter, E. (1990). Augmentative and alternative communication systems for persons with moderate and severe disabilities. Baltimore: Brookes Publishing.

Behrman, M. (1984). A brighter future for early learning through high technology. Pointer, 28, 23-26.
Behrman, M., \& Lahm, E. (Eds.). (1984). Proceedings of the national conference on the use of microcomputers in special education. Reston, VA: Council for Exceptional Children.

Blackstone, S. (1992). For consumers: Rethinking the basics. Augmentative Communication News, 5, 1-3.

Bricker, D. D. (1972). Imitative sign training as a facilitator of word-object association with low-functioning children. American Journal of Mental Deficiency, 76, 509-516.

Bourland, G., Jablonski, E. M., Allen, G. B., \& White, J. (1984). On microcomputers, instruction, and the severely developmentally disabled. In M. M. Behrman \& E. A. Lahm (Eds.), Proceedings of the national conference on the use of microcomputers in special education ( $\mathrm{pp}$. 135-153). Reston, VA: Council for Exceptional Children.

Butler, C. (1985). Effects of powered mobility on self-initiative behavior of very young, locomotor-disabled children. Developmental Medicine \& Child Neurology, 27, 112.

Chamberlain, P. (1985). Increasing the attention span of five mentally handicapped children using their parents as agents of change. Behavioral Psychotherapy, 13, 142-153.

Cone, J. D., Anderson, J. A., Harris, F. C., Goff, D. K., \& Fox, S. R. (1978). Developing and maintaining social interactions in profoundly retarded young males. Journal of Abnormal Child Development, 6 , 351-360.

Esposito, L., \& Campbell, P. H. (1987). Computers and severely and physically handicapped individuals. In J. D. Lindsey (Ed.), Computers and exceptional individuals (pp. 105-124). Columbus, $\mathrm{OH}$ : Charles E. Merrill.

Garner, J. B., \& Campbell, P. H. (1987). Technology for persons with severe disabilities: Practical and ethical considerations. Journal of Special education, 21, 122-132.

Grady, A., Kovach, T., Lange, M., \& Shannon, L. (1991). Promoting choice in selection of assistive devices. Proceedings of the 6th annual technology and persons with disabilities conference (pp. 314-324). Northridge, CA: California State University, AssessAbility Resource Center.

Hagen, D. (1984) Microcomputer resource book for special education. Henderson, MN: Closing the Gap.

Hobson, P. A., \& Duncan, P. (1979). Sign learning and profoundly retarded people. Mental Retardation, 17, 33-37.

Hofmeister, A., \& Friedman, S. (1986). The application of technology to the education of persons with severe handicaps. In R. Horner, L. Meyer, \& B. Fredericks (Eds.), Education of learners with severe handicaps: Exemplary service strategies (pp. 351-368). Baltimore: Paul H. Brookes.

Hulme, J. B., Poor, R., Schulein, M., \& Pezzino, J. (1983). Perceived behavior changes observed with adaptive seating devices and training programs for multi-handicapped, developmentally disabled individuals. Physical Therapy, 63, 204-208.

Hyman, W., Miller, G., \& O'Brien, E. (1988). Evaluation of rehabilitation devices. In Proceedings, ICAART. Montreal, Quebec, Canada.

Kahn, J. V. (1981). A comparison of sign and verbal language training with nonverbal retarded children. Journal of Speech \& Hearing Research, 46, 113-119.

Kostantareas, M. M., Webster, C. C., \& Oxman, J. (1979). Manual language acquisition and its influence on other areas of functioning in four autistic and autistic-like children. Journal of Child Psychology \& Psychiatry, 20, 337-350. 
Locke, P. A., \& Mirenda, P. (1988). A computer-supported communication approach for a child with severe communication, visual, and cognitive impairments: A case study. Augmentative \& Alternative Communication, 4, 15-22.

Lott, W., \& Milner, M. (1984). Evaluations and development of power mobility aids for two- to five-year-olds with neuromuscular skeletal disorders (Final Report Project No. 6606-2114-51). Toronto: Ontario Crippled Children's Center.

McGregor. G., Young, J., Gerak, J., Thomas, B., \& Vogelsberg, R. T. (1992). Increasing functional use of an assistive communication device by a student with severe disabilities. Augmentative \& Alternative Communication, 8, 243-250.

Moore, J. (1991). Technology is not magic. Exceptional Parent, 21, 60-62.

Morrow, L. W., Burke, J. G., \& Buell, B. J. (1985). Effects of a self-recording procedure on the attending to task behavior and academic productivity of adolescents with multiple handicaps. Mental Retardation, 23, 137-141.

Mortola, P., Kohn, J., \& LeBlanc, M. (1988). Implementation and followup of rehabilitation technology. In Proceedings of RESNA 12 annual Conference (pp. 202-203). Washington, DC: Rehabilitation Engineering Center, National Rehabilitation Hospital.

Osborne, S. S., Kosiewicz, M. M., Crumley, E. B., \& Lee, C. (1987). Distractible students use self-monitoring. Teaching Exceptional Children, 19, 66-69.

Phillips, B. (1991). Technology abandonment: From the consumer point of view. Washington, DC: REquest.

Phillips, B. (1992). Perspectives on assistive technology services in vocational rehabilitation: Clients and counselors. Washington, DC: Na- tional Rehabilitation Hospital, Assistive Technology/rehabilitation Engineering Program.

Romski, M. A., \& Sevik, R. A. (1988). Augmentative and alternative communication systems: Considerations for individuals with severe intellectual disabilities. Augmentative \& Alternative Communication, 4, 83-93.

Scherer, M. (1991). Assistive technology use, avoidance and abandonment: What we know so far. Proceedings of the 6th annual technology and persons with disabilities conference (pp. 815-826). Washington, DC: Rehabilitation Engineering Center, National Rehabilitation Hospital.

Scherer, M. (1993). Living in the state of stuck: How technology impacts the lives of people with disabilities. Cambridge, MA: Brookline Books.

Trefler, E., Nickey, J., \& Hobson, D. (1983). Technology in the education of multiply-handicapped children. American Journal of Occupational Therapy, 37, 381-387.

Twardosz, S., \& Jozwiak, W. (1981). The expression of affection: Suggestions for research with developmentally disabled children. Analysis and Intervention in Developmental Disabilities, 1, 217-238.

Verburg, G., Pilkington, M., Snell, E., \& Milner, M. (1985). Providing powered mobility to two- to five-year-olds: The effects on child and family. Developmental Medicine \& Child Neurology, 27, 92.

The information presented in this article was funded by a grant from the Office of Special Education Research, Division of Technology, Educational Media, and Materials for Individuals with Disabilities, CFDA 84.180 .

\section{PERMISSIONS AND COPYRIGHT}

All rights are reserved. No part of this publication may be reproduced, photocopied, faxed, stored in a retrieval system, or transmitted, in any form or by any means, electronic, mechanical, recording or otherwise, without the prior written permission of the publisher.
Back issues are available for sale. Reproduction requires permission and payment of fees. It is illegal and a violation of Federal copyright law to reproduce this publication without permission. Direct all inquiries to the permissions editor. 